EL CONVENTILlo Y LA ViVienda masiva. MEdio Siglo de historia SOBRE LOS ESPACIOS DOMÉSTICOS PARA SECTORES POPULARES, EN EL ÁREA METROPOLITANA DE MENDOZA (ARGENTINA, 1900-1955)

The "Conventillo" And The Mass Housing. Half A Century Of History On Domestic Spaces For Popular Sectors, In The Metropolitan Area Of Mendoza (Argentine, 1900-1955)

\title{
Cecilia Raffa
}

Incihusa - Conicet

craffa@mendoza-conicet.gob.ar

\section{Lorena Manzini}

Incihusa - Conicet

Imanzini@mendoza-conicet.gob.ar

\section{Resumen}

Dónde y cómo se habitaba fueron simultáneamente temasdel ámbito privado y problemáticas de injerencia estatal, como efecto de los cambios sociales, políticos y culturales producidos en las primeras décadas del siglo XX en varios países, incluida Argentina. En esos años, la habitación, la educación y la salud empezaron paulatinamente a ser incorporados a las agendas gubernamentales primero para regularlos, luego para abrirlos a los sectores de menores recursos tras el objetivo de la democratización del bienestar. Paralelamente, la renta de habitaciones y la autoconstrucción se mantuvieron como estrategias de larga duración para acceder a la vivienda, a través de variadas tipologías. El trabajo propone, sobre la base del método histórico, trazar una historia de los espacios domésticos en el Área Metropolitana de Mendoza, analizando las condicionantes de su producción y poniendo en relación la acción privada y la estatal.

\section{Palabras claves}

espacio doméstico, acción estatal, acción privada

\section{Abstract}


Where and how were simultaneously lived private sphere issues and problems of state interference, the effect of social, political and cultural changes in the first decades of the twentieth century in several countries, including Argentina. In those years, the room, education and health gradually began to be incorporated into government agendas to regulate first, then to open them to sectors with fewer resources after the objective welfare of democratization. In parallel, the rent of rooms and self remained as long-term strategies to access housing through various typologies. The paper proposes, on the basis of the historical method, trace a history of domestic space in the Metropolitan Area of Mendoza, analyzing the factors of production and by linking private action and state.

\section{Keywords}

domestic space, state action, private action

\section{Acción privada y acción estatal. Operaciones paralelas}

El comienzo del siglo XX trajo aparejado para muchos de los Estados Modernos, el rápido crecimiento de sus principales centros urbanos, a consecuencia de la incesante migración rural hacia las ciudades en busca de trabajo y una mejor calidad de vida, la evolución de la ciencia y un veloz aumento de las actividades industriales que tuvieron en el operario el engranaje fundamental de la producción. En Argentina debemos sumar a estos fenómenos la gran corriente inmigratoria de fines del siglo XIX, que fue modificando la composición social e incidiendo en los aspectos espaciales de las ciudades. ${ }^{1}$

El ferrocarril y el tranvía, como modernos sistemas de transporte, fueron los que vehiculizaron la entrada de capital y tecnología a las ciudades, además de permitir el movimiento de personas en importantes proporciones (LIERNUR, 1987).

En nuestro país, la población rural se multiplicó por cuatro desde 1869 y la urbana aumentó catorce veces. Estas "masas", se concentraron en los suburbios urbanos. Suburbios en general modestos, que fueron la residencia de muchas personas que tuvieron en las capitales y sus alrededores su ocupación habitual.

\footnotetext{
${ }^{1}$ Entre 1880 y 1910 llegaron al país cuatro millones de inmigrantes, de los cuales el mayor porcentaje se radicó en las principales ciudades argentinas. Entre 1936 y 1947, más de un millón de personas del interior se desplazaron hacia las ciudades, empujadas por los desfavorables términos de intercambio económico interno.
} 
Esa concentración urbana trajo consigo el ineludible problema del alojamiento.

En torno a esta problemática es que se desarrollaron, particularmente en Buenos Aires, y a partir de la aparición del partido radical en el ámbito nacional y el comienzo de la organización de la clase obrera hacia mediados de la década del ' 10 , una serie de propuestas vinculadas a la construcción de conjuntos de viviendas, individuales o colectivas, para albergar a trabajadores que hasta el momento se alojaban en conventillos o ranchos(LIERNUR, 1987).

Asociaciones, cooperativas e iniciativas patronales, sumadas a una incipiente acción estatal a nivel nacional, ${ }^{2}$ llevaron a cabo algunos de esos planteos.

La primera mitad del siglo $\mathrm{XX}$, fue un período de reflexión, discusión y experimentación en torno al tema de la vivienda para sectores sociales bajos. El Estado mismo propició un centro de regulación de la vivienda popular a través de la creación de la Comisión Nacional de Casas Baratas en $1915,{ }^{3}$ que aunque con un número escaso de concreciones en lo arquitectónico; permitió la formación de técnicos en el extranjero y la difusión del tema en congresos y conferencias (CIRVINI, 2004, p.171).

La vivienda popular se transformaba así, en un instrumento dentro de las políticas de transformación social, concebido para alentar ciertas prácticas y dificultar otras (RIGOTTI, 1985).

Hasta 1920, esta temática fue tratada mayoritariamente por reformadores sociales, políticos y médicos, primero y por ingenieros después, que buscaron nuevas "formas de habitar" en reemplazo de las tradicionales casas de patios y conventillos. Pero desde mediados de esa década el interés por la vivienda popular, fue creciendo dentro de la disciplina arquitectónica.

Hubo un importante desarrollo conceptual y teórico.

\footnotetext{
${ }^{2}$ Hacemos referencia a la ley Garzón Maceda de 1907 que financiaba obras administradas y construidas por una institución de beneficencia, o la ley 4824/05 propuesta por el diputado Irigoyen, que asignaba fondos de la Municipalidad de Buenos Aires para la construcción de viviendas. BALLENT, Anahí (2004), Vivienda de interés social: Aliata, Fernando y Liernur, Francisco (dir.) Diccionario Histórico de Arquitectura, Hábitat y Urbanismo en la Argentina, Buenos Aires: Clarín, tomo s-z, p. 176.

3 La Comisión Nacional de Casas Baratas fue creada mediante ley 9677 en 1915. Proponía un programa destinado a proveer viviendas a los sectores de menos recursos. La ley, iniciativa del diputado Cafferata, establecía una Comisión, integrada por cinco miembros ad honorem designados por el Poder Ejecutivo, que tendrían funciones de fomento, dirección y control de viviendas con base en un fondo creado ya por la ley 7102. En veintiocho artículos se legislaba lo esencial de la materia para que la Comisión iniciara sus trabajos. Lo novedoso consistía, entre otras razones, en que preveía un seguro temporario de vida a favor del adquirente de una casa barata, mediante una cuota mínima, para garantizar a su familia, en caso de muerte, el pago de todas las cuotas que faltaren para la escrituración. Los destinatarios de los beneficios de ley eran en este orden: obreros, empleados de escaso sueldo, contribuyentes de cuotas mínimas AAVV (1957). Anales de Legislación Argentina (1889-1919), Buenos Aires: Ed. La ley, p. 946- 947.
} 
En base al conocimiento de los modelos de post- guerra europeos, pero también del debate nacional en torno a la vivienda; los arquitectos comenzaron a trabajar sobre aspectos técnicos referidos particularmente al plano funcional (distribución, asoleamiento, agrupamiento, dimensionamiento); al plano constructivo (estandarización, industrialización) y a los recursos económicos (financiamiento, cooperativismo, planes estatales, etc.). El debate giraba también, en torno a la acción que el Estado debía realizar, a si las viviendas debían ser colectivas o individuales, a si debían ser en propiedad o en alquiler, etc.

Ese interés por la modernización del hábitat, la industrialización de la construcción y la necesidad del abaratamiento de la vivienda para el "alojamiento popular", hacen que algunos estados provinciales a través de sus cuadros técnicos, comiencen a plantear su intervención en el tema habitacional a través de políticas públicas (naciente Estado de bienestar) que tuvieron como objetivo contrarrestar las desigualdades sociales, en este caso las referidas a la vivienda.

Los movimientos poblacionales delas periferias a los centros, como hemos mencionado, generaron en el Área Metropolitana de Mendoza ${ }^{4}$ un déficit habitacional alto, por lo cual resultó imperioso para la gestión conservadora (1932-1943), pero sobre todo para la peronista (1946-1955) avanzar en la solución de esta problemática.

Por fuera de la acción estatal, la falta de soporte habitacional para el hospedaje de los nuevos habitantes urbanos, dio lugar a que familias completas arrendaran habitaciones en antiguas casonas organizadas en torno a patios conocidas como conventillos.

En Mendoza, como en la mayoría de las principales ciudades argentinas, el conventillo fue la tipología más difundida, también la criticada por los higienistas. Sin embargo existieron otras variantes tipológicas de la habitación de bajo costo como la casa de vecindad, de departamentos o Pasajes -producto de inversiones de capital para renta- y los ranchos -expresión tradicional y precaria de difusión urbana y rural- . En la ciudad se ofrecieron además, otra serie de alternativas, a veces transitorias, como eran los hoteles, el Asilo de Inmigrantes y los alojamientos anexos a las "comiderías" que también tuvieron un importante papel como solución al alojamiento popular (CIRVINI, 1989).

\footnotetext{
${ }^{4}$ El Área Metropolitana de Mendoza (AMM) está comprendida en la actualidad por los seis departamentos que definen el conurbano: Capital, Godoy Cruz, Guaymallén, Luján, Maipú y Las Heras. Constituye la cuarta aglomeración de la Argentina actual, luego de Buenos Aires, Córdoba y Rosario.
} 


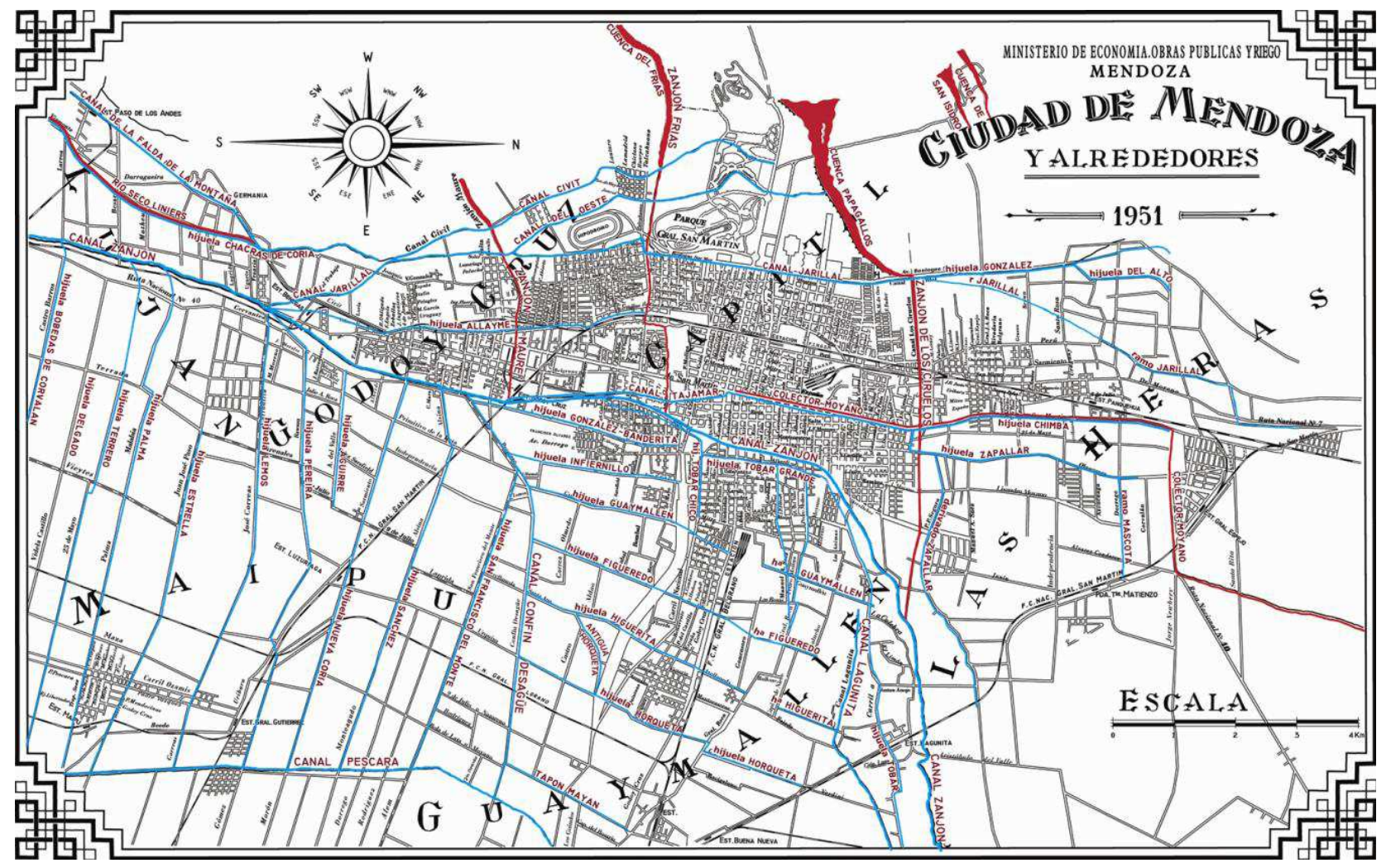

FIGURA 1: Área metropolitana de Mendoza hacia mediados del siglo XX. Fuente: Ponte, 2007

La autoconstrucción fue una acción clave en la edificación del espacio doméstico de los sectores populares ${ }^{5}$ que adquirían lotes en zonas periféricas como la Ciudad Vieja,

\footnotetext{
${ }^{5}$ Sectores populares (tanto como elite) son distinciones analíticas que se utilizan para estudiar a la sociedad en su conjunto. En este trabajo pretendemos estudiar a la sociedad y sus aspectos culturales (formas de producción, consumo) desde la perspectiva de uno de sus actores: los sectores populares, una categoría que no es entendemos como monolítica (sus límites son difusos) sino más bien como instrumental. ROMERO, Luis Alberto (1990). Los sectores populares urbanos como sujetos históricos: Proposiciones $n^{\circ} 19$, Ediciones sur: Santiago de Chile, pp.28-278.
}

URBANA, V.6, no 8, jun.2014 - Dossiê: Cidade e Habitação na América Latina - CIEC/UNICAMP 
actual $4^{\circ}$ sección, ${ }^{6}$ o en tramos no consolidados dentro de los departamentos vecinos a la ciudad capital. Esta estrategia hacía posible el sueño de la casa propia ya que las viviendas eran construidas por los integrantes de cada familia, de acuerdo a sus necesidades y posibilidades económicas. La tipología habitacional más difundida que se empleó en la autoconstrucción fue la casa en hilera o chorizo que tiene sus raíces en la casa de patio tradicional (LIERNUR, 1987).

Los sectores sociales bajosde Mendoza, optaron por continuar construyendo con esta tipología habitacional durante las primeras décadas del siglo XX, ya que respondía con eficiencia a la posibilidad de albergar familias complejas y extendidas, además deconvertirse en una fuente de recursos económicos a partir del alquiler de algunos de sus numerosos cuartoscomo hospedaje o para la instalación de comercios o talleres. En cierta medida, esta tipología habitacional actuó como integradora de la pluralidad social, ya que fue empleada también por los sectores medios urbanos en zonas más centrales.

Pero esta forma de habitar también fue foco de críticas por parte de especialistas y dirigentes. Las observaciones que se hacían estaban relacionadas con 4 puntos fundamentales: el alto grado de vinculación del dominio estrictamente privado con el espacio público; su carácter lineal, carente de un foco espacial que condensara el conjunto de actividades familiares; la indiferenciación de sus cuartos seriados vinculados a través de una vía de circulación, lo que suprimía cualquier posibilidad de individualidad o privacidad de sus habitantes, yel sistema higiénico ineficaz que poseían (LIERNUR, 1987).

Las críticas sobre esta tipología fomentaron estudios y propuestas técnicos que dieron más tarde origen a dos nuevos tipos: por un lado la vivienda obrera colectiva, por el otro las casas individuales y compactas. Este último, aplicado masivamente durante el gobierno peronista en la construcción de barrios jardín (ABOY, 2005), iría marcando la fisonomía de nuevas zonas residenciales urbanas, relacionando directamente los espacios

\footnotetext{
${ }^{6}$ Mendoza, Nuevo Valle de Rioja (1561), fue una de las primeras fundaciones en el actual territorio de la República Argentina en el piedemonte de la cordillera de los Andes, oasis irrigado del Río Mendoza. La ciudad de Mendoza tuvo un lento crecimiento de tres siglos hasta el destructivo terremoto de 1861 que la dejó en ruinas. Reconstrucción, Inmigración y Modernización fueron los ingredientes de un vertiginoso crecimiento hacia fines del siglo XIX. Mendoza tuvo ( $y$ tiene) dos zonas urbanas claramente diferenciadas desde el traslado del emplazamiento original de la ciudad post-terremoto hacia el oeste del territorio provincial. Por un lado están la Ciudad Nueva con centro en la plaza Independencia, por el otro la plaza Pedro del Castillo, centro del antiguo núcleo colonial conocido como Ciudad Vieja. La dicotomía política y social entre las dos ciudades y sus espacios públicos se ha visto reflejada a lo largo de toda la historia urbana mendocina. RAFFA, Cecilia (2009b). La ciudad comunicada. Análisis de la incidencia de las representaciones políticas y técnicas en la conformación y permanencia de los imaginarios sobre el espacio público moderno: el caso de las plazas fundacionales (Mendoza 1910-1943).Tesis doctoral. Mendoza: FCPyS - UNCuyo, inédito.
} 
físicos de la vivienda y los modos de habitarla: el espacio doméstico (SANCHEZ, 2008), y marcando un nuevo estadio de la acción estatal sobre el ámbito de lo privado.

El trabajo propone a partir del abordaje de fuentes primarias y secundarias y de la consulta de literatura crítica sobre el tema, un recorrido por este doble juegodel desarrollo de los espacios domésticos urbanos: los que la propia gente construye o adapta y los impulsados por el Estado.El espacio físico de las viviendas y los modos de habitarla irán articulando "la cuestión de la vivienda" como conjunto de problemas económicos, políticos, culturales y sociales propio de las sociedades modernas.

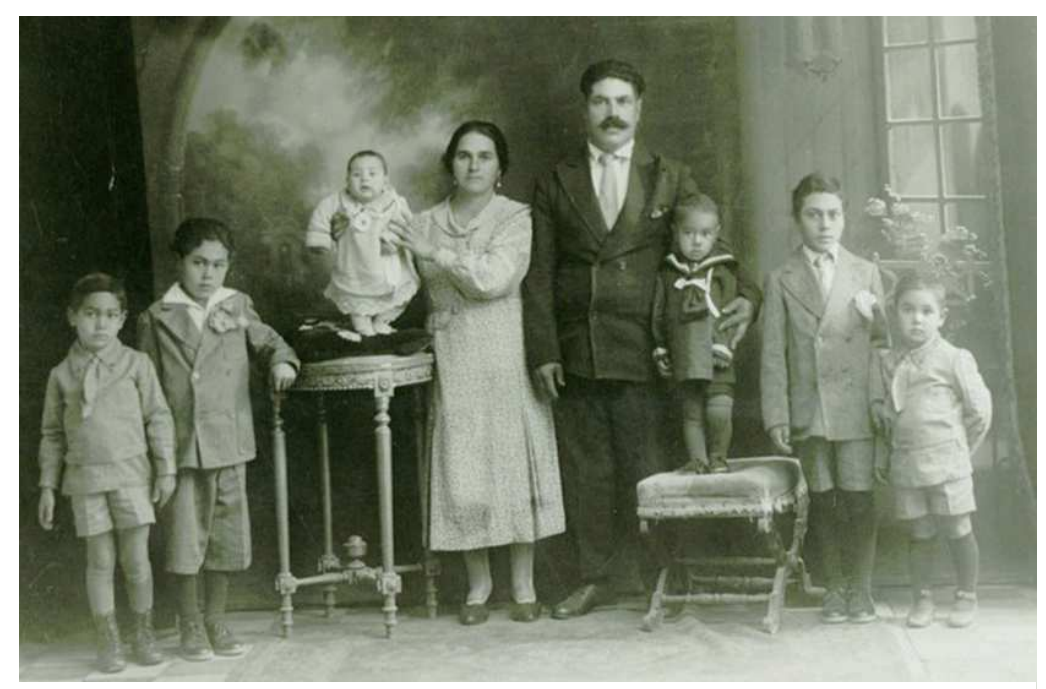

FIGURA 2: Familia de inmigrantes de Origen italianos. Fuente archivo particular Familia Celi, 1920 c

\section{La vivienda popular en el ámbito privado: conventillos, casas de vecindad y casas chorizo}

La modernización iniciada a fines del siglo XIX tuvo entre sus consecuencias el acelerado proceso de urbanización de la zona central en Mendoza. Los inmigrantes que llegaban a la ciudad capital, no encontraron soporte habitacional para su hospedaje, lo que dio lugar a que familias completas arrendaran habitaciones en antiguas casonas organizadas en torno a patios: los conventillos.

Los conventillos o inquilinatos actuaron como los primeros espacios domésticos. A ellos se accedía a través de la renta de habitaciones, como solución "transitoria" a la falta de una vivienda propia. Era considerado conventillo o inquilinato toda casa donde se alojaran más de dos familias. A cada familia le correspondía usualmente una habitación, 
y los servicios sanitarios, si existían, eran escasos, 1 cada 10 habitaciones, y de uso compartido. (LECUONA, 1993)

El conventillo fue, sin duda, la solución más difundida, la más representativa de la época. Los conventillos fueron considerados, como en el resto del país, "focos de infección", como también lugares propicios para el desarrollo de los vicios, la vagancia, la suciedad, la prostitución. De allí que, de la crítica higienista - apoyada en el discurso médico- se transitara a una prédica moralizadora en relación a las costumbres, los hábitos y la vida cotidiana.

En el análisis de la problemática de los conventillos es necesario considerar dos aspectos diferentes aunque dependientes: uno era su ubicación espacial en la ciudad, y el otro las características intrínsecas de los edificios.

La localización de inquilinatos y conventillos en la traza urbana revela el origen de la preocupación oficial en el tema. Hacia fines de siglo, el emplazamiento de las dos estaciones de ferrocarril (Gran Oeste Argentino y Trasandino) sobre calle Belgrano, en el borde oeste y más elevado de la ciudad de Mendoza, había estimulado la instalación de conventillos en sus márgenes, cuyas malas condiciones higiénicas determinaban que, a causa de las pendientes de las acequias, las enfermedades infecciosas "bajaran" a la ciudad. A propósito de ello el primer caso de la gran epidemia de cólera de 1886/87 se registró en un conventillo de la calle Belgrano. (CIRVINI 1989)

De acuerdo al Censo Sanitario de la Habitación elaborado por Emilio Coni, conocido como Informe Coni y publicado como Saneamiento de Mendoza (1897), la mayor concentración de inquilinatos se registraba en las inmediaciones del ferrocarril, particularmente en las calles Belgrano (51 inquilinatos) y Perú (27), donde superaban con amplitud a las "casas de familia". En la Sección Este (Ciudad Vieja) las calles con mayor número de inquilinatos eran: Ituzaingo (35), Montecaseros (37), Salta (34) y hasta la propia Avda. San Martín concentraba un elevado número (78).

Los inquilinatos y conventillos eran insalubres por las deficiencias edilicias, el hacinamiento y la carencia de servicios. Instalados generalmente en antiguas casonas, a cada familia le correspondía una habitación de no más de 20 o $25 \mathrm{~m} 2$, con un índice promedio de ocupación de 5 personas. Los muros de adobes, carentes de mantenimiento eran nido de insectos. El uso del patio para múltiples actividades desde laborales a domésticas compensaba la escasez de espacio de las habitaciones. Sin embargo, también esto era fuente de conflictos y disturbios. Sobre esta condición del espacio común en los 
conventillos, se asentarán las críticas y las miradas de higienistas, funcionarios y políticos que veían en ese espacio el semillero de conflictos y malos hábitos de los sectores populares. No era tan solo la precariedad, y la pobreza de los medios de vida de los habitantes lo que preocupaba sino su incidencia en la vida colectiva, los ranchos de la Chimba o de los bordes del Zanjón ${ }^{7}$ eran tan insalubres como los conventillos pero estaban fuera de la mirada oficial y de la trama más consolidada de la ciudad capital. (CIRVINI 1989)

A partir del Informe Coni, la autoridad municipal se sintió obligada a intervenir y se aprobaron las primeras normas tendientes a modificar la situación sanitaria, lo que dio origen en 1902, al primer Reglamento General de Construcciones que estableció la sujeción a sus normas a los edificios para casas de vecindad y conventillos y, lo que es más importante, determinó la obligatoriedad de una inspección municipal para la habilitación de todo tipo de inquilinatos.

Es difícil evaluar si mejoraron las condiciones de vida en ellos con la injerencia de la autoridad municipal. Es claro, sin embargo, que se fue estructurando un sistema de control que antes no existía. Esta disposición, unida a otras dos ordenanzas de ese mismo año, referidas a la obligatoria instalación de servicios sanitarios en el área urbana servida por el agua corriente, tendieron a modificar en gran medida la situación de la habitación popular. Sin embargo, las normas de higienización de conventillos en la ciudad no consiguieron sino desplazar el problema de las áreas centrales a la periferia, tal cual había sucedido con el equipamiento urbano "indeseable": matadero, cementerio, quema de basuras, lazaretos, etc., que fueron instalándose en los departamentos aledaños principalmente Las Heras y Guaymallén.

En los primeros años del siglo $X X$, dentro del municipio capitalino se redujo notablemente el número de conventillos e inquilinatos, a pesar de que la población continuaba en sostenido aumento a causa de las crecientes migraciones internas. Consideramos que esto puede haber sido consecuencia de una serie de inhabilitaciones municipales por malas condiciones higiénicas y edilicias, o porque se tornó no rentable para los propietarios adecuar los edificios a los nuevos requerimientos. Así, según el Censo Municipal de 1903, los inquilinatos que quedaban en el área urbana servida por aguas corrientes eran muy pocos (cerca del $6 \%$ del total de la ciudad). Probablemente

\footnotetext{
${ }^{7}$ La Chimba era la denominación que se le daba a la zona limítrofe entre los departamentos de Mendoza y Las Heras. En nuestra época de estudio eran considerados suburbios.
} 
entonces, los controles y exigencias sanitarias consiguieron desplazar los conventillos a zonas más alejadas, a gran parte de la Sección Este (Ciudad Vieja) y en los suburbios, donde la vigilancia sanitaria era menos rigurosa y la autoridad municipal más tolerante.

En 1909 se sancionó la primera ordenanza municipal específica sobre inquilinatos, determinándose como norma general y obligatoria condiciones de higiene y habitabilidad mínimas (CIRVINI, 1989) A ello se le suma que en 1911 por ordenanza municipal se extiende el área decente de la ciudad. ${ }^{8}$
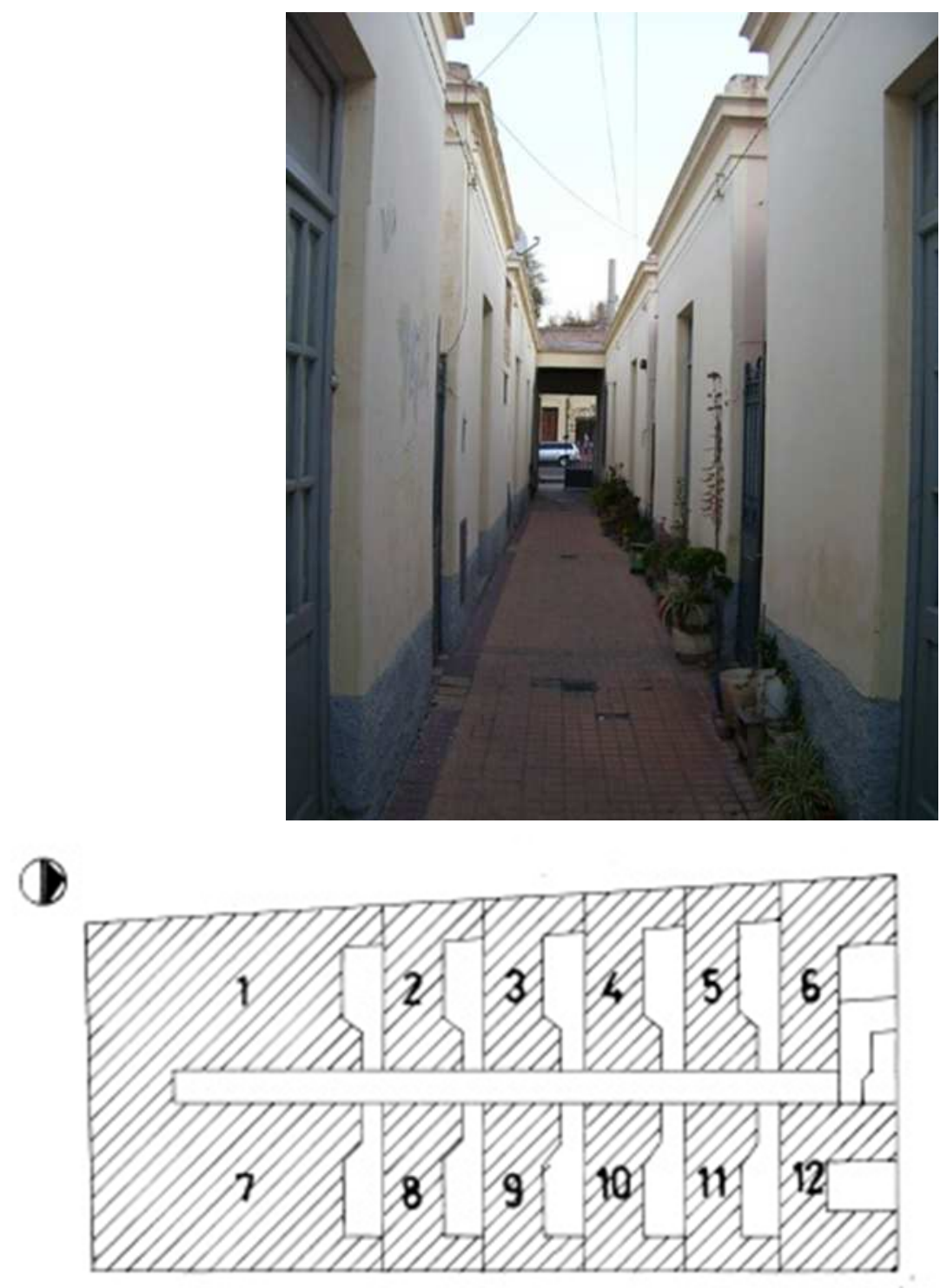

${ }^{8}$ Los nuevos límites son al norte calle Alberti; al este calle Ituzaingo y canal Zanjón; al sur: calle Colón y José Vicente Zapata y al oeste: calle Boulogne Sur Mer. Digesto Municipal de la Ciudad de Mendoza (18691913). (1914) Mendoza. Imprenta la tarde p.109 
Figuras 3 y 4: Casa de Vecindad circa 1915. Ubicada en calle Juan B. Justo № 169 - 183. Fotografía actual y esquema de planta.

Fuente: archivo AHTER - INCIHUSA CONICET

La casa de vecindad, fue una opción "superadora" del conventillo.

La casa de vecindad y de departamentos o pasaje, fue un conjunto de unidades habitacionales mínimas e independientes alineadas, consideradas como un espacio doméstico transitorio que en algunos casos se convertía en permanente. Compuesta por una serie alineada de unidades habitacionales independientes donde se compartía el acceso común y a veces los servicios, esta tipología de vivienda colectiva, fue propia del habitar de la modernidad de los sectores populares desde 1885. Su tipología fue muy difundida a principios del siglo XX en las proximidades de la Estación del FC. ${ }^{9}$

La casa de vecindad era considerado el inquilinato "de cuello duro" en referencia a que los inquilinos tenían una posición privilegiada dentro de la clase obrera ya que los alquileres eran aquí superiores a otros grandes alojamientos de la zona como el conventillo. (CIRVINI, 1989)

La casas en "hilera", Ilamadas también casas "chorizo" o "Las casas de piezas" correspondieron a fines del siglo XIX y principio del siglo XX, a las viviendas de las clases populares y medias. Constituyeron la unidad de un tejido urbano homogéneo de vastos sectores residenciales. La casa chorizo se caracterizó por ser una tipología integradora de la pluralidad social, en especial de las últimas décadas del siglo XIX y las primeras del siglo XX. (DE GREGORIO, 2006)

Esta tipología habitacional que se extendió a lo largo de toda la trama urbana de la actual Área Metropolitana de Mendoza, fue el resultado de un proceso de síntesis entre la tradición criolla de casas solariegas, de patios, galerías y huertas y el aporte cultural de la inmigración italiana que adapta a las nuevas condiciones de producción, en lotes

\footnotetext{
${ }^{9}$ Existe un solo ejemplo de esta tipología aún en pie en la ciudad de Mendoza. La casa se encuentra en una zona urbana de alta densidad en la histórica calle Juan B. Justo (prolongación de Av. Las Heras al oeste). Esta arteria históricamente poseía numerosos edificios como éste y también numerosos conventillos. Sobre esta calle también se ubicaba el Hotel de Inmigrantes, en las proximidades de la Estación de Pasajes del Ferrocarril Andino adonde llegaban desde 1885 los inmigrantes. Cuenta con 12 unidades locativas (las dos frontales destinadas a uso comercial) con un pasillo central. La fachada al ras de línea municipal posee un portón de acceso y su corriente estilística se resuelve en un lenguaje simplificado del neoclásico tardío habitual en la arquitectura doméstica tradicional de la ciudad. Este estilo caracterizó la arquitectura de Mendoza hasta aproximadamente 1910 debido a que la mayoría de los constructores y técnicos locales también eran de procedencia italiana. La casa de vecindad posee muros de ladrillo, techos de correas y cabios de madera. Mantiene aún su función original lo que contribuye a su conservación.
} 
urbanos estrechos y profundos y con un ordenamiento espacial tanto de las plantas como de las fachadas, más riguroso y modulado. En general se resolvían en una sola planta, con fachada a ras de línea municipal, ingreso a través de un zaguán y con galerías y locales cuadrando patios.

La tipología de la "casa chorizo" tuvo una gran versatilidad y se adaptó a distintas situaciones urbanas y diferentes épocas. La autoconstrucción fue la estrategia usual desplegada por los sectores populares para levantar y luego ir ampliando este tipo de vivienda. La mediación profesional era mínima y restringida a los constructores de oficio
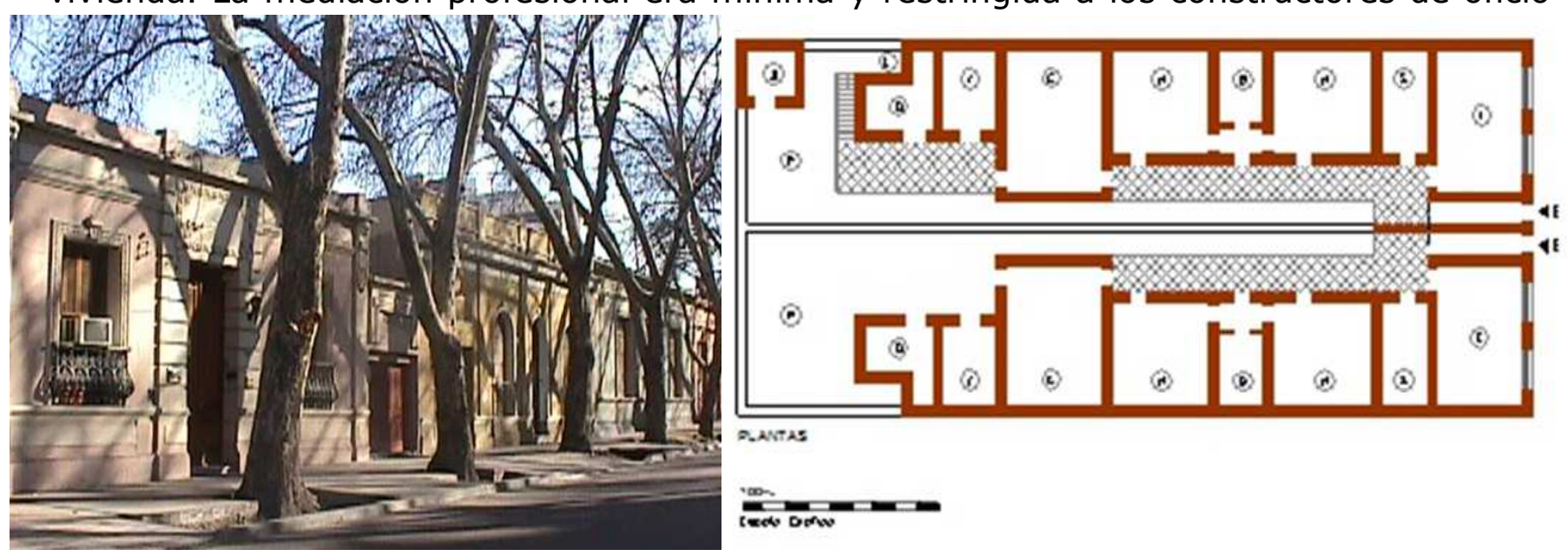

Figuras 5 y 6: Casa chorizo circa 1920. Fotografía actual y esquema de planta. Fuente: archivo AHTER - INCIHUSA CONICET

y a los artesanos como los carpinteros o frentistas.

La construcción era habitualmente de adobes, techos de madera y las más modernas con cubiertas de zinc. En algunos casos las fachadas se construyeron de ladrillo cocido a la vista, lo cual constituía todo un indicador de pertenencia a un nivel social superior.

La casa típica se estructura en tres sectores funcionales: uno frontal contiene el área de uso social: recepción y sala (a veces también un comercio), uno en hilera con la galería adosada que constituye el sector principal de la casa con las habitaciones y el comedor generalmente cerrando el primer patio, y uno posterior hacia los fondos que contiene los servicios (cocina, lavadero, baño, etc.) ${ }^{10}$

\footnotetext{
${ }^{10}$ Como resultado de entrevistas a propietarios mendocinos, podríamos decir que en las casas existía un orden jerárquico, un código social preestablecido en la posibilidad de acceder a los espacios de la vivienda vinculados con las relaciones de amistad y de parejas. MANZINI, Lorena, (2011). Las viviendas del siglo XIX en Santiago de Chile y la región de Cuyo en Argentina: Revista Universum. № 26 Vol. 2, pp. 165 a 186.
}

URBANA, V.6, no 8, jun.2014 - Dossiê: Cidade e Habitação na América Latina - CIEC/UNICAMP 
Aunque las hubo de diferentes calidades este tipo de vivienda fue netamente popular y tenía la ventaja del progresivo crecimiento a medida que las necesidades de la familia aumentaban, agregando habitaciones a la hilera principal. (BORMIDA ET AL, 1990)

En términos generales estas tipologías relacionadas a la autoconstrucción y la renta donde los sectores populares habitaron, se ubicaron en las inmediaciones del ferrocarril y sus calles vinculadas, como también en los bordes de las zonas urbanas consolidadas. En las primeras décadas del siglo XX las calles Belgrano, Perú y Juan B. Justo son las arterias en las que se ubicaron conventillos o Inquilinatos dando origen a zonas netamente habitacionales. En la Ciudad Vieja las calles más importantes por mayor concentración de conventillos fueron Ituzaingo, Montecaseros y la Avenida San Martín. Posteriormente a mediados del siglo XX las calles ejes en la conformación de las áreas residenciales populares son Paso de los Andes y Jorge a Calle, actualmente incorporadas a la 5 y $6^{\circ}$ sección de la ciudad de Mendoza. ${ }^{11}$

\section{Acerca de la vivienda y la acción estatal}

Las primeras preocupaciones del Estado respecto de la vivienda pueden ubicarse, como hemos mencionado, en la segunda mitad del siglo XIX cuando las epidemias, como la de cólera que se propagó en Mendoza entre noviembre de 1866 y marzo de 1867, hicieron que los sectores urbanos, donde la población vivía en condiciones de marginación comenzaran a despertar el interés de los médicos higienistas y los dirigentes.

Es entonces que la higiene, urbana y humana, empieza a tomar importancia como instrumento de intervención preventivo y a la vez disciplinador, convirtiéndose en parte del progreso y la civilización (ARMUS, 2000).

La irrupción pública del Higienismo está vinculada con la voluntad centralizadora del Estado y con sus intentos de "homogeneización ciudadana", a través de diversas instituciones, al tiempo que constituye un pilar ideológico en la circulación de un conjunto de representaciones sobre el cuerpo, la salud y el ambiente, compartidas por la clase dirigente, los expertos y algunos ciudadanos (particularmente de las clases altas) y que se extiende a diversos aspectos de la vida cotidiana.

\footnotetext{
${ }^{11}$ Estas conclusiones derivan de los estudios realizados en el marco del proyecto PICT 20080484 "Rutas e Itinerarios Culturales" a partir del relevamiento de bienes habitacionales y estudios históricos sobre los planos de la ciudad de Mendoza de los años 1872; 1881; 1885; 1903; 1912; 1925; 1930; 1940 y 1951. 
La provisión de agua potable y la eliminación de desechos; la especificación y ampliación de los reglamentos de control de las industrias; el alejamiento del centro urbano y la reglamentación de los espacios considerados peligrosos como los cementerios; la delineación de calles y la creación de espacios verdes, fueron parte de las acciones que se llevaron a cabo en las principales ciudades argentinas en el ámbito de lo público.

Las observaciones de tono moral y las indicaciones físicas que empezaron a generarse desde la esfera estatal respecto del espacio doméstico fueron constituyéndose en la base de todas las intervenciones que desde el ámbito estatal o institucional, abordarían el tema de la vivienda como instrumento de reforma social durante las dos primeras décadas del siglo XX (BALLENT, 2004, p. 177).

Es recién avanzado los años treinta, que Mendoza se convierte en una de las primeras provincias argentinas en trabajar desde el aparato estatal sobre la modernización y mejora del hábitat y la necesidad del abaratamiento de la vivienda para el "alojamiento popular".

Entre 1932 y 1943, Mendoza es gobernada por una sucesión de políticos provenientes del Partido Demócrata, ${ }^{12}$ cuyas acciones de gobierno se centraron en el emprendimiento de obras públicas de infraestructura básica, como caminos, puentes y diques y la atención de áreas como la salud, educación y vivienda.

El período en sí, presenta cierta homogeneidad en lo que a lineamientos, planificación y ejecución de Obra Pública se refiere. Esa continuidad es la que permitió que en un lapso relativamente corto(1935-1938) y con el paso de dos gobernadores, Guillermo Cano y Rodolfo Corominas Segura, se materializara el proyecto de las Casas Colectivas, primer pueblo para empleados y obreros modestos.

Hacia 1935, los arquitectos Manuel y Arturo Civit ${ }^{13}$ a cargo de lo que luego sería la Dirección Provincial de Arquitectura, proponen al entonces gobernador Cano, la

\footnotetext{
12 Hacemos referencia a las gobernaciones de Ricardo Videla (1932-1935), Guillermo Cano (1935-1938), Rodolfo Corominas Segura (1938-1941) y Adolfo Vicchi (1941-1943)

13 Arturo Civit (Buenos Aires 1903- Mendoza 1975).Arquitecto graduado en la Universidad de Buenos Aires en 1928. En 1932 se instala en Mendoza donde desarrolla junto a su hermano Manuel, una intensa labor profesional tanto en forma particular como desde la función pública. Entre 1932 y 1943 ocupó alternativamente con Manuel los cargos de director y vicedirector de la Dirección de Arquitectura de la Provincia de Mendoza. Manuel Civit (Buenos Aires 1901- Mendoza 1978).Arquitecto graduado en la Universidad de Buenos Aires en 1926. Viaja por Europa, con su hermano Arturo, donde toman contacto con las nuevas tendencias del racionalismo alemán. A partir de su radicación en Mendoza en 1932, desarrolla junto a su hermano Arturo, una intensa labor profesional en la que se destaca el vanguardismo con que conciben el producto arquitectónico y su adhesión al Movimiento Moderno. Sus obras se encuadraron en un planteo social de avanzada. Promovieron y realizaron el Primer barrio Obrero de la provincia y numerosas
} 
construcción de un pueblo de Casas Colectivas. A partir de entonces, del precedente establecido por la Comisión Nacional de Casas Baratas (que operó exclusivamente en Buenos Aires) y de la posibilidad de auto- abastecimiento de materiales de construcción (cemento y acero), es que en la provincia comienzan a implementarse las leyes referidas a la construcción de "casas colectivas e individuales para empleados y obreros modestos", como parte de la acción estatal (RAFFA, 2006).

La operación apuntaba a modificar la forma de vida del sector más humilde de la población, conformada por un importante número de migrantes concentrados en torno al centro urbano que forma la capital. La preocupación del gobierno estaba puesta no en el alto porcentaje de la población formada por los inmigrantes que se ya se habían ubicado en los conventillos y las viviendas auto- construidas. Sino en los "argentinos nativos" que migraban desde la zona rural hacia la ciudad de Mendoza. Población que se asentó tanto en el municipio capitalino, como en la amplia zona circundante que comprendía los departamentos de Godoy Cruz, Luján, Guaymallén y Las Heras y que conformaban con la capital una unidad vital -económica (CANO, 1935).

Hasta ese momento, la vivienda popular se había desarrollado en Mendoza, con escasa mediación profesional. El inquilinato, generalmente en antiguas casas subarrendadas a varias familias; las casas de vecindad, de departamentos o pasajes y la casa individual, de patios o en hilera en la ciudad y rancho en la periferia, eran las tipologías corrientes (CIRVINI, 1989).

Ubicadas en el sector noroeste de la actual $6^{\circ}$ sección sobre la Av. Boulogne Sur Mer y muy cerca del Parque San Martín, las Casas Colectivas se levantaron como una de las más ambiciosas obras emprendidas por el gobernador Cano durante sus años de gestión, constituyéndose al mismo tiempo en la primera respuesta concreta que el gobierno provincial daba al problema habitacional, particularmente al de la vivienda para los sectores de más bajos recursos. Dentro de ese sector los empleados estatales aparecían como una franja de ingreso mínimo, pero estable.

El proyecto de los Civit avalado por Cano fue expuesto en un mensaje elevado por el gobernador a la Legislatura en septiembre de 1935. El dirigente, esgrime las

construcciones sanitarias, hospitalarias, educativas y asistenciales. Durante su trayectoria profesional los Civit pasaron de la más ortodoxa postura racionalista a un pintoresquismo doméstico, generalmente californiano, que empieza a aparecer en su producción hacia 1936. RAFFA, Cecilia (2009) La vanguardia racionalista en Mendoza: la obra de los arquitectos Manuel y Arturo Civit: Revista de Historia de América no 139, Costa Rica: IPGH- OEA, pp. 23-35 
causas por las cuales el Estado debe hacerse cargo del "albergue confortable $y$ económico", para los componentes más humildes de la comunidad. Los bajos salarios para la compra de la casa propia por parte de los trabajadores y la proliferación de los conventillos eran parte

de esas razones.Los males que produce la "mala vivienda" serían contenidos ahora por el bienestar que produce un hogar estable y feliz. A lo largo de su argumento, Cano va intercalando razones cercanas a la moralidad, la higiene, el confort y la economía. Entiende que es el Estado Moderno quien debe cumplir una función social ineludible a favor de las clases menos afortunadas y decidir su intervención directa en la construcción de viviendas populares. ${ }^{14}$

Si bien para el gobernador las casas individuales satisfacían el ideal del hogar propio, confortable e independiente; las ventajas de las colectivas respecto de una operatoria estatal son un menor costo (mejor aprovechamiento de los recursos invertidos por el Estado); un alquiler inferior (mayor alcance popular); menos terreno para mayor número de habitantes (aprovechamiento de suelo); la centralización de todos los servicios generales (economía de recursos); la provisión de calefacción y agua caliente y la facilidad de control administrativo.

La propuesta del conjunto que habían presentado los Civit al gobernador Cano en febrero de 1935 se inspiró en la obra cumplida en el exterior de miles de casas colectivas para el alojamiento de grandes masas de obreros. El proyecto se concibió teniendo en cuenta que el problema de la vivienda mínima era "originado por la mecanización siempre creciente de la vida, por el perfeccionamiento en el confort y la técnica moderna y por los impostergables dictados de la salubridad científica que trata de salvar las reservas vitales de la Nación (...)" (CIVIT Y CIVIT, 1937, p. 274).

El conjunto con capacidad para 3000 personas fue ideado en blocks de 14 casas colectivas con 727 departamentos en total, aunque finalmente el conjunto se redujo y se construyeron 576 departamentos (RAFFA, 2006).

Se incluyó en la propuesta el planteo urbanístico correspondiente a la construcción de amplias calles y veredas- jardines que separarían a los pabellones entre sí y que ligaban el tratamiento de la vivienda obrera al urbanismo y por ende a la ciudad.

\footnotetext{
${ }^{14}$ En el mensaje el gobernador se refiere al fomento de la vivienda realizado a partir de tres tipos de procedimiento: la iniciativa privada como El Hogar obrero en Buenos Aires; la acción mixta, mediante subsidios estatales e iniciativas particulares como las que se realizan en Inglaterra, Francia y Estados Unidos y las estatales como la ley nacional 9677 o la edificación a gran escala que se hace en Rusia o Alemania. CANO, Guillermo(1935).Labor Gubernativa, tomo n ${ }^{2} 2$, septiembre- octubre, p. 15- 17.
} 
Se previó además, la construcción de un pabellón de administración, consultorio médico y casa cuna, para que las madres que trabajan puedan dejar los niños pequeños bajo la vigilancia técnica; un local para la instalación de calderas y tanques para el servicio de instalación de calefacción y agua caliente central, parque de juego para niños, gimnasio y pileta de natación; equipamiento comunitario, que terminaba de constituir al conjunto en un verdadero pueblo. En una utopía de unidad autosuficiente.

Como núcleo estaba el departamento mínimo.

Los departamentos independientes entre sí, tendrían estructura antisísmica de ho armado, mampostería de ladrillo, instalación de calefacción y agua caliente central; lavadero mecánico, luz eléctrica y artefactos eléctricos instalados. Baño y cocina con artefactos y accesorios, obras sanitarias, ventanas y celosías metálicas, puertas de madera terciada, cielos rasos de yeso, pisos de madera y mosaicos, roperos, armarios y bibliotecas embutidos, amueblamiento completo con camas sillas y mesas.

Se proyectaron tres tipos de departamentos mínimos, con uno, dos o tres dormitorios, con capacidad de tres a siete camas y con un living- room, donde podría habilitarse una cama más. Esto teniendo en cuenta las estadísticas del Departamento Nacional de trabajo que estimaban que el término medio de los componentes de las familias obreras es de alrededor de cuatro personas.

En cuanto al conjunto, los departamentos se repartieron en edificios de planta baja y dos pisos altos con una superficie cubierta para cada edificio de $3000 \mathrm{~m}^{2}$ repartidos uniformemente en cada uno de los tres pisos. Cada block tendría aproximadamente 52 departamentos, ${ }^{15}$ con superficies de $44,65 \mathrm{~m}^{2} ; 54,75 \mathrm{~m}^{2}$ o 68,60 $\mathrm{m}^{2}$ según el número de dormitorios.

Parapermitir el asoleamiento de los edificios y parte de las calles en cualquier época del año, se calculó una separación entre los bloques bastante amplia. El pueblo estaría rodeado por cuatro calles principales.

${ }^{15}$ Esta cifra disminuyó al momento de la construcción definitiva. Cada bloque podía llegar a tener hasta 42 departamentos, dependiendo la superficie de las unidades. 

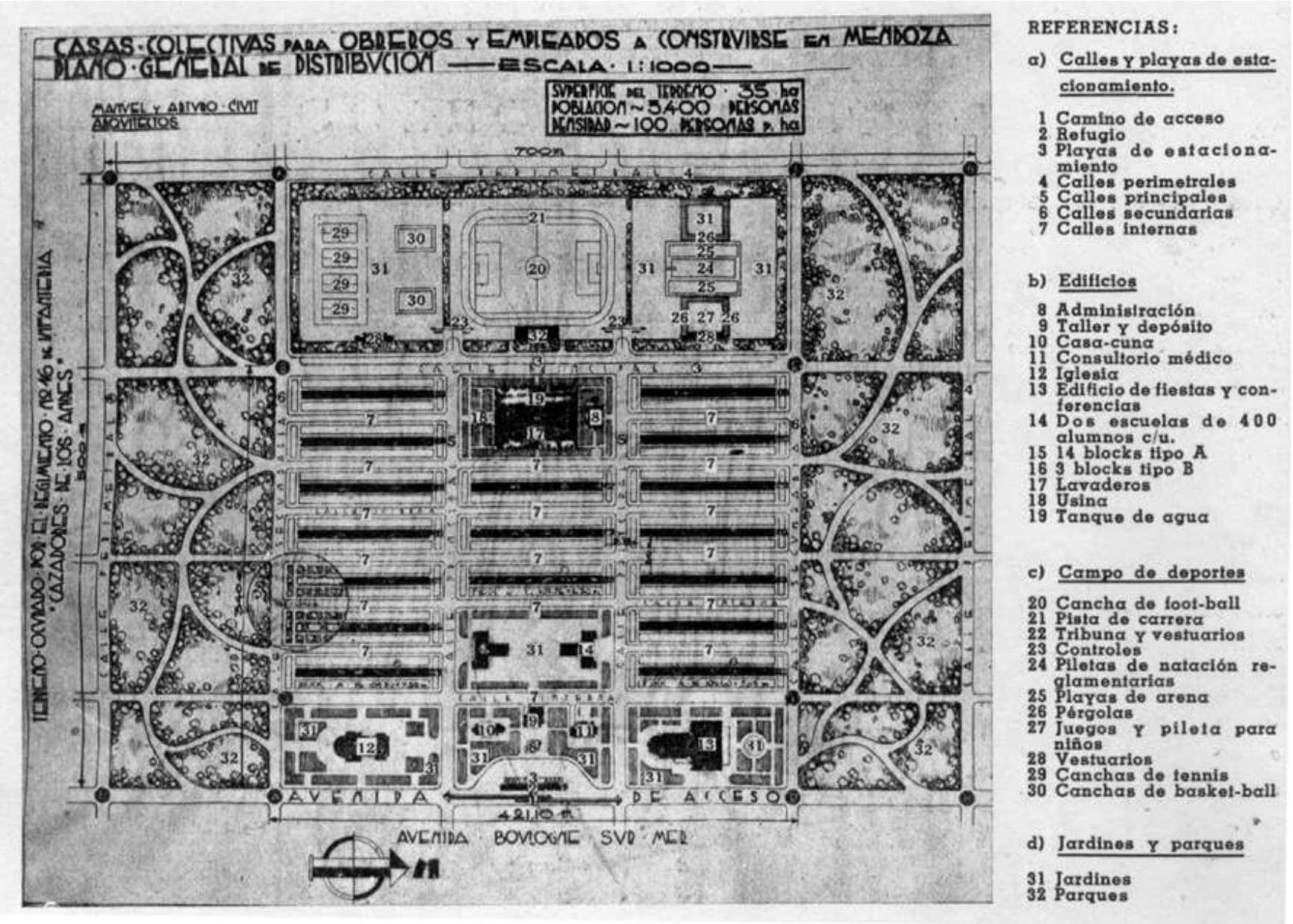

FIGURA 7: Planimetría del conjunto según proyecto de 1935 . Fuente: Nuestra Arquitectura n8, 1937

En el mes de agosto de 1937, el Ministro de Industria y Obras Públicas Frank Romero Day eleva un mensaje a la Comisión Provincial de Casas Colectivas, a fin de obtener una propuesta de reglamentación por parte de la misma:

(...) el propósito del gobierno es, no sólo ofrecer alojamiento higiénico, confortable y barato, a los servidores modestos del Estado, sino crear una verdadera escuela de vivienda, que vaya formando un ambiente propicio para instituir más adelante un organismo proveedor de casas propias. Para ello, es indispensable que la vida en las casas colectivas se organice con la visión del propósito perseguido, a cuyo efecto debe pensarse desde ya en la reglamentación que corresponda (CANO, 1937). 
El propósito de crear una verdadera escuela de vivienda, puede leerse claramente en los 39 artículos contenidos en "el manual para habitar el pueblo de casas colectivas", que marcaba disposiciones morales y estéticas.

El primero de los puntos abordados en ese dispositivo modelador fue el del acceso al arriendo de las viviendas. Condición ineludible era la de ser empleado modesto u obrero del Estado, pensionado o jubilado público.

Los interesados con estas características, debían llenar una solicitud de arriendo que sería evaluada por la Comisión, la que decidiría la adjudicación de las viviendas priorizando a las familias más numerosas, las de mejores antecedentes, las que se encuentren "peor" alojadas, a los argentinos nativos, las familias de mayor residencia en la provincia y las que posean muebles más adecuados (DIAZ GUZMAN, 1938, p. 32).

Se fijan mediante este decreto, los montos de los alquileres de acuerdo a la cantidad de habitaciones de las unidades, como también las medidas disciplinarias a aplicar por parte de la Administración en los casos del mal uso del equipamiento comunitario, o el deterioro de alguna de las unidades. ${ }^{16}$

El pueblo para 3000 habitantes, se convirtió en el único prototipo en bloque, durante más de cuarenta años de vivienda popular en la provincia. No obstante ello, nunca cumplió con la misión de ser un pueblo- escuela de vivienda popular.

El primer año no hubo más de treinta familias ocupando los 42 departamentos que ya se habían inaugurado, a pesar de que se habían anulado la serie de limitaciones en lo referente al derecho de ocupar los departamentos y que los alquileres eran relativamente bajos.

\footnotetext{
${ }^{16}$ Se prevé en los artículos del Capítulo II de Régimen Interno, una serie de disposiciones prohibitivas (disciplinarias) de todo aquello que atente contra una convivencia comunitaria armoniosa, como son los actos contrarios a la moral y las buenas costumbres, los gritos, discusiones políticas, religiosas o gremiales; las fiestas o festejos que perturben a los vecinos; el uso de aparatos de radiofonía, fonógrafos, etc. después de las 22 horas en días laborales y de las 24 horas en vísperas de día festivo; la instalación en los departamentos de talleres, guardado de frutas, verduras o carnes para vender en el interior del "pueblo" o fuera de él; la instalación de antenas u ocupación alguna de la azoteas. La Administración, a cargo de la Comisión provincial de Casas económicas ejercerá sus funciones a través de un administrador, un contador y un auxiliar; y será la encargada del control general del predio y de decidir qué tipo de muebles pueden ingresarse a los departamentos a fin de evitar acumulaciones antiestéticas o antihigiénicas. Debe además recibir los reportes sobre cualquier enfermedad infecciosa o grave que ocurra dentro del ámbito de cada familia. Los animales domésticos serían tolerados, sólo si están sanos y limpios y no implican peligro para los vecinos. De fundamental preocupación para la Comisión era "todo lo concerniente a profilaxis, higiene y educación de los habitantes". Para ello sedetermina, en el capítulo IV del Reglamento, la afectación de un grupo de visitadoras sociales (la mirada del Estado) al pueblo de Casas Colectivas, que ejercerían una permanente vigilancia en cuanto a las enfermedades infecto- contagiosas, y cuyas indicaciones deberían ser cumplidas por todos los arrendatariosbajo pena de desalojo. DÍAZ GUZMÁN, José (1938). Índice general de leyes de la provincia (1896- 1946), $2^{\circ}$ serie, tomo VII (1926-1937).
} 
La falta de construcción de la mayoría del equipamiento comunitario que proponía este proyecto (iglesia, escuela, casa cuna), las deficiencias en el transporte público que unía el "pueblo" con el centro de la ciudad; la carencia de conexiones telefónicas, de servicios médicos, de proveedurías cercanas y los problemas en el servicio de calefacción, fueron algunas de las razones que hicieron que hasta el año '45 y como consecuencia del déficit habitacional en la capital de la provincia, las Casas Colectivas no estuvieran totalmente ocupadas.

Los estratos medios de la población mendocina fueron los que finalmente accedieron a estas casas de renta que poco a poco y debido a la baja recuperación de la inversión estatal por la escasa recaudación de alquileres, pasaron a manos de particulares.
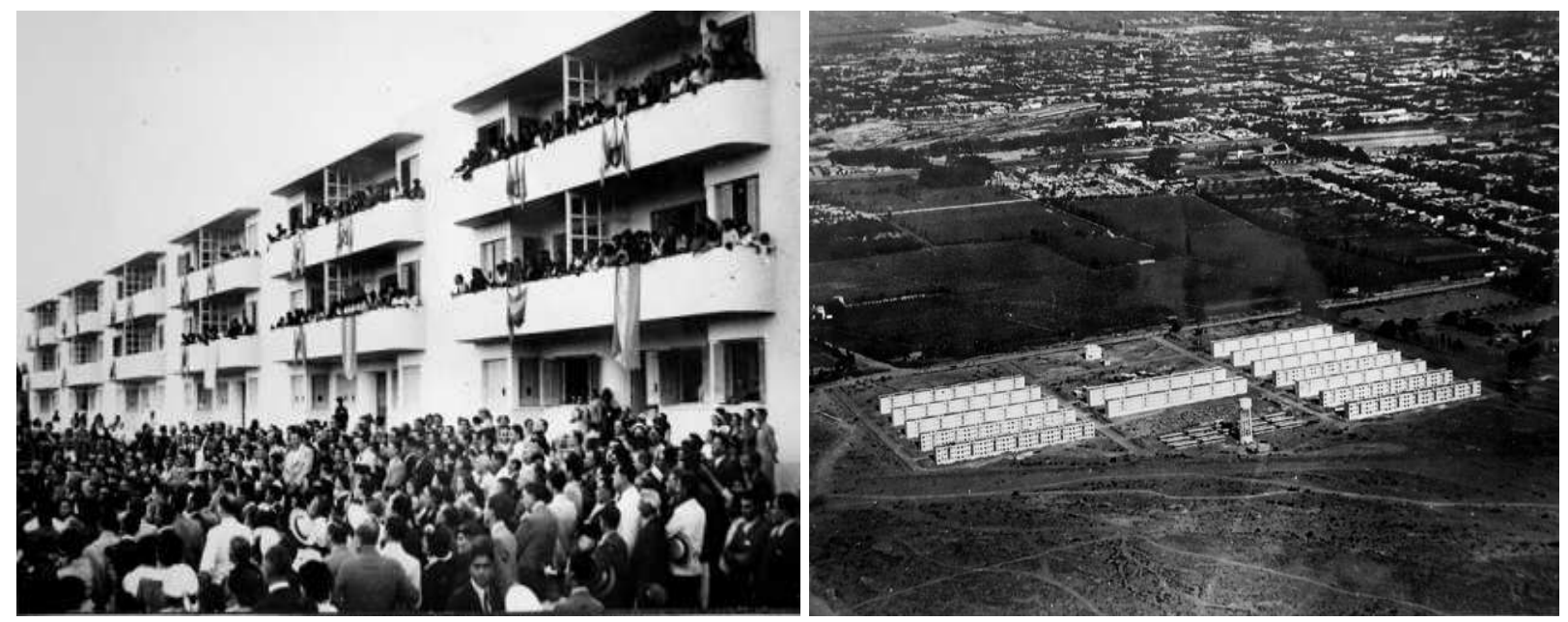

FIGURAS 8 Y 9: Inauguración de las Casas Colectivas (1938) y vista del conjunto(1940 c). Fuente: ARCHIVO HISTÓRICO DE MENDOZA

Además de la construcción de las Casas Colectivas de arriendo, la legislatura amplió el proyecto contenido en la ley $n^{\circ} 1190$ a la construcción de casas jardines individuales de arriendo en los centros más poblados de los demás departamentos de la provincia y de casas granjaque serían vendidas bajo el régimen de la Ley del Hogar. ${ }^{17}$ De la construcción y administración de estos tres tipos de vivienda económica debía ocuparse la Comisión Provincial de Casas Económicas, posiblemente el primer antecedente del Instituto Provincial de la Vivienda creado luego por la gestión peronista local (RAFFA, 2006).

\footnotetext{
${ }^{17}$ Esta ley promulgada en 1934, contemplaba la exención impositiva a las propiedades que se adhirieran a la Ley Nacional 10293.
} 
Esta Comisión, estaba compuesta de cinco personas funcionarios o no, designadas por el Poder Ejecutivo y tendía a su cargo el estudio de los proyectos, planos y presupuestos que confeccionara la Dirección de Arquitectura de la Provincia; la superintendencia de la construcción de las casas económicas (casas jardines, casas granja, etc.) y su administración.

De acuerdo a una propaganda del Partido Demócrata Nacional publicado en uno de los periódicos locales en vísperas de las elecciones de $1946,{ }^{18}$ el Barrio 4 de junio, ubicado en la actual $6^{\circ}$ sección en las inmediaciones de las Casas Colectivas, fue también parte de la iniciativa conservadora dentro de la tipología de casas jardín. Es probable que el conjunto haya estado en plena construcción al momento de producirse la revolución nacional el 4 de junio de 1943, a partir de la cual los gobiernos conservadores nacionales y provinciales fueron destituidos. De ahí podría surgir el nombre del barrio y la identificación de esta obra con la gestión peronista.

Dentro de las memorias de gobierno del período conservador se incluye un anteproyecto de una "casa para peón caminero", que se ubicaría, según consta en los planos, a la vera de las vías de circulación vehicular.

Entendemos que esta propuesta continúa el espíritu de las Colectivas de dotar de vivienda a los trabajadores del Estado, en este caso los vinculados a la construcción y el mantenimiento de rutas y caminos, aunque probablemente en calidad de préstamo o sesión temporal por parte del Estado. La casa estaba compuesta por dos dormitorios, comedor diario, baño, cocina y living-room. Se accedía a ella a través de una galería y tenía garaje para tres vehículos (seguramente contemplando el guardado de maquinarias para el trabajo de construcción o reparación de caminos).

\footnotetext{
${ }^{18}$ Diario Los Andes, 10 de febrero de 1946, p. 6 y 7 

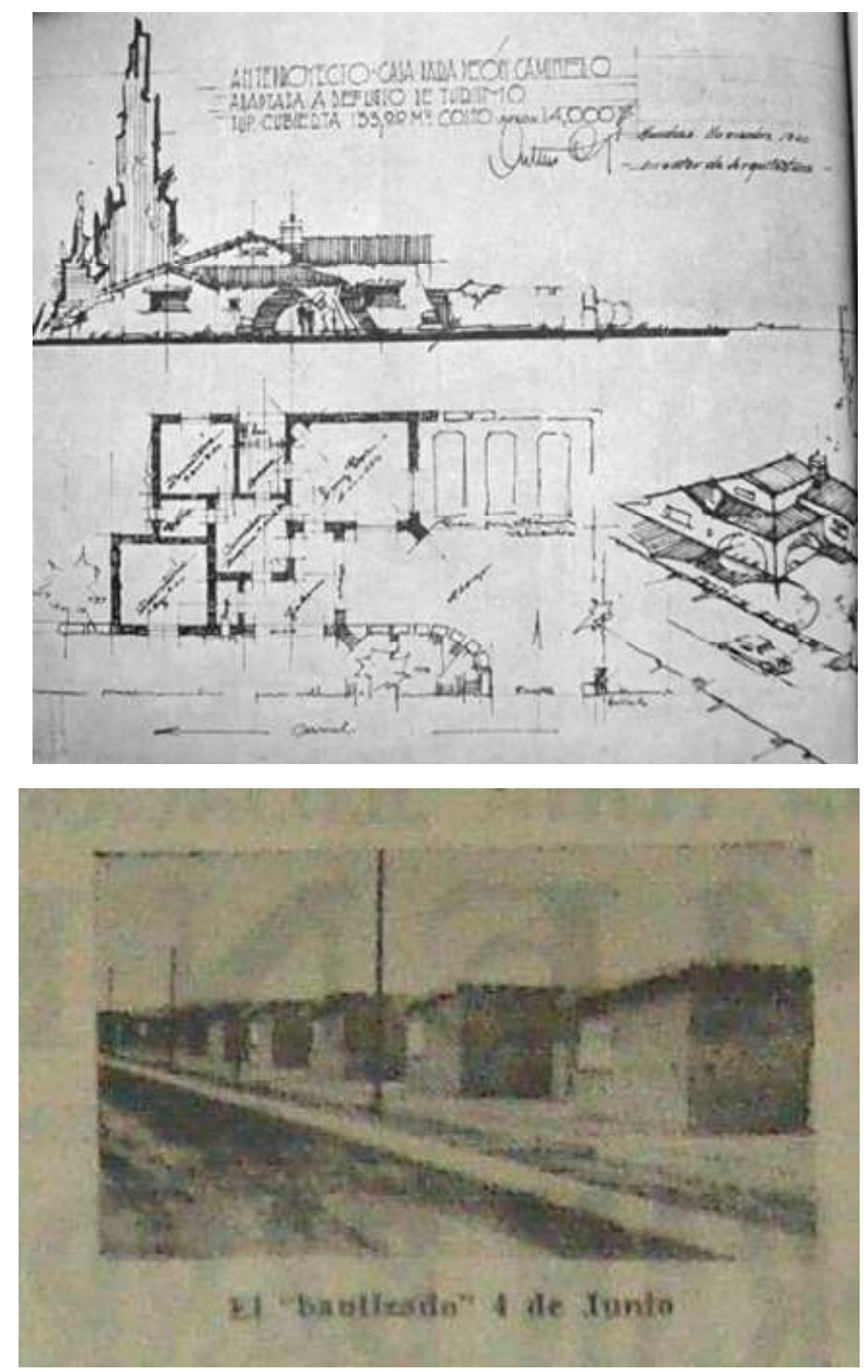

FIGURAS 10 Y 11: Anteproyecto "casa peón caminero" y El barrio bautizado "4 de junio". Fuente: DIARIO LOS ANDES, 1946 y COROMINAS SEGURA, 1942

El anteproyecto datado en 1940, incluso tiene la particularidad de ser "adaptable" a la función de albergue turístico. ${ }^{19}$

El debate y las acciones que se desarrollaron hasta los años' 40 sobre la vivienda popular constituyeron una de las condiciones de posibilidad de las políticas peronistas: fueron la base a partir de la cual se pensó en la construcción masiva (BALLENT, 2005, p. 31)

\footnotetext{
${ }^{19}$ No hemos podido rastrear la concreción de ninguno de estos prototipos de vivienda. 
En el lapso que va de 1946 a 1955, las administraciones peronistas ${ }^{20}$ acentuaron el papel del Estado y de su intervención en la vida social, económica y cultural de la provincia. La labor del gobierno de Mendoza en el período peronista giró en torno a tres conceptos fundamentales: agua, vivienda y salud que se convirtieron en pivote del bienestar y la seguridad social.

El estímulo oficial provincial, inserto en los planes quinquenales diseñados por el gobierno nacional, potenció la obra pública manifestándose en la ampliación de las redes camineras e hidráulicas existentes, en la construcción de centrales hidroeléctricas y en la explotación petrolera a través de YPF, entre otros. El ciclo de prosperidad de los primeros años peronistas, caracterizado por el pleno empleo y la distribución de la renta nacional que alcanzó a familias obreras y de las clases medias, se manifestó en el reemplazo del adobe por el ladrillo en las viviendas populares.

El régimen de construcción de viviendas encarado por el Gobierno de Mendoza, impulsó la propiedad de las unidades de habitación por parte del obrero o empleado de modestos recursos, sin que para ello necesitara desembolsos iniciales y facilitando el pago a través de cuotas mensuales inferiores al alquiler de un inmueble de similares características.

El plan de financiación adoptado en la mayoría de los casos consistía en la adquisición de terrenos por parte del gobierno provincial para que sobre ellos se levantasen los edificios con préstamos del Banco Hipotecario Nacional, órgano centralizador de la financiación de la vivienda popular a partir de la modificación de su carta orgánica en 1947 y de la nacionalización del sistema bancario (BALLENT, 2004, p.182).

En 1947, el peronismo local al mando del gobernador Faustino Picallo, inició su acción en esta temática, con la creación del Instituto Provincial de la Vivienda (IPV), organismo que se ocuparía de atender el problema de la vivienda de los sectores de menores ingresos.

Sancionada la Ley $N^{\circ} 1658 / 47$, el IPV comenzó su vida institucional dependiendo del entonces Ministerio de Economía, Obras Públicas y Riego y funcionando a través de un Fondo Permanente de Vivienda. Este fondo se constituía con aportes de todos los empleadores de la provincia y fue denominado "Impuesto de acción social".

\footnotetext{
${ }^{20}$ Los gobernadores de este período fueron: Faustino Picallo (1946-1949), Blas Brisoli (1949-1952) y Carlos Evans (1952-1955).

URBANA, V.6, n० 8, jun.2014 - Dossiê: Cidade e Habitação na América Latina - CIEC/UNICAMP
} 
Entre las funciones establecidas para el Instituto estaba la de administrar el conjunto de Casas Colectivas, el Barrio 4 de Junio y todas las viviendas que el Estado construyera en adelante; además de planificar y realizar la construcción de viviendas económicas, antisísmicas tanto urbanas como rurales para su venta o arrendamiento especialmente a familias limitadas de recursos; promover mediante estímulos, asesoramientos, franquicias y créditos la construcción particular de viviendas económicas antisísmicas; propulsar el saneamiento y la renovación de la vivienda popular.

Las viviendas "armoniosas, confortables y uniformes" proyectadas desde las oficinas técnicas, se entregaban con la instalación de gas natural y los artefactos correspondientes (cocina, calefón y estufa), tenían jardines y una pequeña fracción de terrenos en los fondos "utilizable para la plantación de legumbres o para la crianza de animales domésticos" (OFICINA DE PRENSA, 1951).

Fueron parte del plan de viviendas los Barrios 4 de Junio (finalización de obra) y María Eva Duarte de Perón (1948 primera etapa, 1949 se escritura la segunda) -luego denominado Barrio Ferroviario-, en la ciudad capital; el Barrio Perón- luego conocido como Ejército de los Andes- (1952 se concluyó la primera etapa y se inició la segunda) y Ferroviarios Belgrano (se inicia en 1954) en Guaymallén; la denominada Villa Evita con un total de 1200 casas programadas en la zona de Villa Hipódromo, destinadas a obreros y empleados de YPF, de la Compañía Electricidad de Los Andes, suboficiales del Ejército, empleados de comercio y empleados de correo (682 viviendas terminadas a junio de 1954 ); los Barrios Bancario (1949) y 17 de octubre - luego Laprida-, también en Godoy Cruz.

\begin{tabular}{|c|c|c|}
\hline Barrio 4 de junio: & 119 viviendas & Mendoza \\
\hline Barrio María Eva Duarte de Perón (1loteo): & 200 viviendas & Mendoza \\
\hline Barrio María Eva Duarte de Perón (2॰loteo): & 364 viviendas & Mendoza \\
\hline Barrio Presidente Perón (1이oteo): & 100 viviendas & Guaymallén \\
\hline Barrio Presidente Perón ( $2^{\circ}$ loteo): & 174 viviendas & Guaymallén \\
\hline Barrio 17 de octubre: & 17 viviendas & Godoy Cruz \\
\hline Villa Evita $\left(1^{\circ}\right.$ loteo $)$ & 682 viviendas & Godoy Cruz \\
\hline Villa Evita ( $2^{\circ}$ Ioteo): & 521 viviendas & Godoy Cruz \\
\hline Ferroviarios Belgrano: & 80 viviendas & Guaymallén \\
\hline
\end{tabular}


Barrio Vialidad Provincial:

Total de viviendas:

(1): Se consignan los nombres originales de los barrios; la cantidad de viviendas previstas es indicativa.

CUADRO 1: Viviendas previstas para Mendoza en el marco del Primer Plan Quinquenal. Elaboración CR sobre datos publicados en: OFICINA DE PRENSA (1951)

Con alta densidad poblacional, de buena calidad ambiental, en la mayoría de los casos la implantación de estos barrios rigió la estructura de crecimiento urbano de las zonas aledañas al estar dotados de todas las redes de servicios, tener calles asfaltadas y poseer equipamiento público como plazas, escuelas y en algunos casos, centro de salud. Las viviendas que se construyeron eran del tipo cajón compactas con espacios de funciones diferenciadas que permitían el confort en el habitar.

La casa cubría un rol fundamental en las estrategias de distinción de las familias nucleares trabajadoras. Estas identificaban el acceso a los modos del habitar de la clase media como un elemento clave en su trayectoria familiar: la relación era casa- familiastatus. 


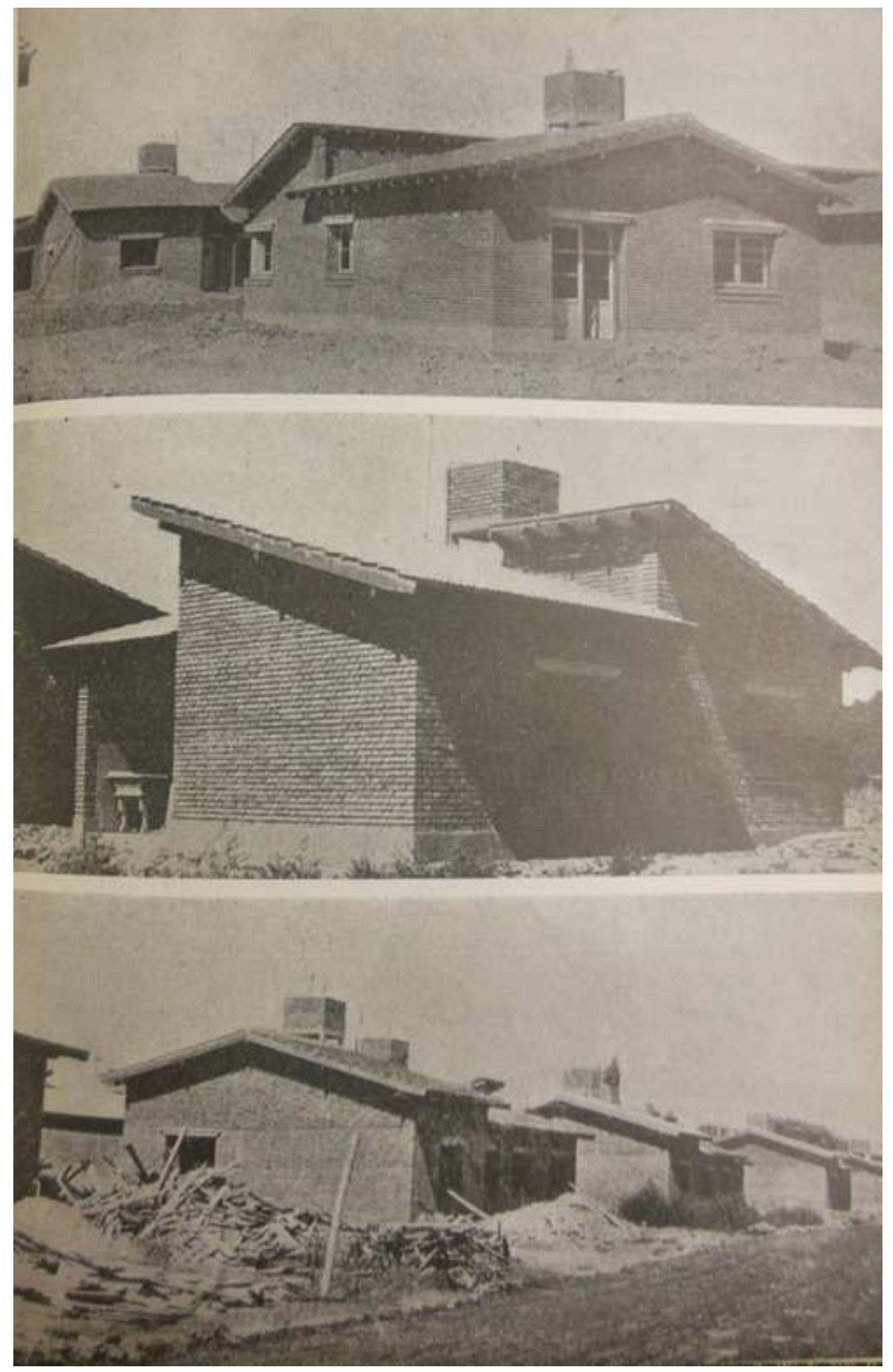

FIGURA 12: Barrio Presidente Perón, luego Ejército de Los Andes en Guaymallén. Fuente: OFICINA DE PRENSA (1951)

La adquisición de estas casas cristalizó un nuevo modelo de domesticidad cuyas pretendidas cualidades fueron la austeridad en el consumo, la racionalidad en el uso del dinero, la previsión en la planificación familiar, el saber y el cuidado en el uso de los bienes adquiridos (BALLENT, 2005):

(...) es así como muchos obreros mendocinos son hoy felices poseedores de la casita limpia y confortable, que además de favorecer el establecimiento de un 
hogar digno, representa la estabilización económica y la posesión de un bien que cubra al núcleo familiar de riesgos futuros (OFICINA DE PRENSA, 1951, p. 20).

El 4 de junio de 1954, el gobernador Carlos Evans, de conformidad con lo prescripto en la Constitución Provincial, expuso ante la Legislatura provincial el estado general de la administración y el desarrollo de los planes de Gobierno. Entre los temas abordados, estuvo el de la vivienda.

Al referirse a esta problemática Evans anunció la previsión dentro presupuesto extraordinario de 50 millones de pesos financiables con la concurrencia del Banco Hipotecario, el Instituto Nacional de Previsión Social, el Banco de Mendoza y el IPV, que elevaban la cifra de viviendas a construir en 1954 a mil unidades. Pero el énfasis del mensaje estuvo puesto en la financiación que la provincia recibiría a través del Plan Eva Perón ${ }^{21}$ a un "revolucionario proyecto de técnicos oficiales mendocinos, gracias al cual podrán construirse viviendas -incluido terreno- a un costo total de treinta mil pesos, equivalente a una amortización mensual de 156 pesos" (EVANS, 1954, p.30).

\begin{tabular}{|c|c|c|}
\hline Barrio Ferroviario & 49 viviendas & Luján de Cuyo \\
\hline Suboficiales del Ejército & 170 viviendas & $\begin{array}{l}\text { Godoy Cruz (incluido } \\
\text { en Villa Evita) }\end{array}$ \\
\hline Para servidores del Estado & sin datos & $\begin{array}{l}\text { Mendoza } \\
\text { (inmediaciones del } \\
\text { Barrio } 4 \text { de junio) }\end{array}$ \\
\hline Empleados provinciales & 200 viviendas & Sin ubicación \\
\hline Barrio 17 de octubre & 200 viviendas & San Rafael \\
\hline $\begin{array}{l}\text { Barrio Ferroviario } \\
\text { Barrio empleados de }\end{array}$ & 50 viviendas & San Rafael \\
\hline Comercio & 100 viviendas & al Alvear \\
\hline
\end{tabular}

Total de viviendas previstas

769 viviendas

Otros barrios previstos: Para empleados del Ministerio de Economía, para empleados de la Universidad Nacional de Cuyo.

\footnotetext{
${ }^{21}$ En octubre de 1952, meses después del fallecimiento de Eva Duarte de Perón, se iniciaron los préstamos del Plan Eva Perón que financiaba la construcción de viviendas individuales. Sus destinatarios eran obreros y empleados comprendidos en las leyes de previsión social cuyos ingresos no superaran los $\$ 2000$ mensuales. A diferencia de los planes encarados en los primeros años peronistas que se identificaban con la construcción directa de conjuntos, el Plan consideraba la célula individual como la base de su estrategia.BALLENT, Anahí (2005). Las huellas de la política. Vivienda, ciudad, peronismo en Buenos Aires, 1943 - 1955, Buenos Aires: UNQ, pp. 88-91.
}

URBANA, V.6, no 8, jun.2014 - Dossiê: Cidade e Habitação na América Latina - CIEC/UNICAMP 
CUADRO 2: Viviendas previstas para Mendoza en el marco del Segundo Plan Quinquenal. Elaboración CR sobre datos publicados en: EVANS (1954)

El mensaje dado por el gobernador Evans a la Legislatura un año después, en 1955, connota los difíciles momentos económicos y sociales que el país y la provincia atravesaban.

Para el mes de abril de 1955, se habían entregado según los datos brindados por el gobernador: 85 casas del Barrio Ferroviario Belgrano y 36 del Barrio de Oficiales; 392 casas estaban en construcción, 260 licitadas y 183 habían sido proyectadas para iniciarse en ese año, entre las que se contaban 21 casas en el departamento de La Paz.

La exención de impuestos a las construcciones del plan "Eva Perón", unido a la financiación del Banco Hipotecario colaboraron en el avance, aunque menor que en los primeros años peronistas, del objetivo político de que cada familia argentina tuviera un techo "decente" (EVANS, 1955)

Un nuevo Golpe de Estado perpetrado en septiembre de 1955, interrumpió la conclusión de muchas de las propuestas de viviendas encaradas por el Estado provincial.

Algunas fueron retomadas por los gobiernos posteriores, los sindicatos o los mismos adjudicatarios organizados en cooperativas. En todos los casos se cambiaron los nombres originalmente designados para los conjuntos, pretendiendo borrando todo rastro de su origen peronista.

El primer Plan Quinquenal ${ }^{22}$ propuso la sanción de la Ley de propiedad horizontal 13512/48, que establecía la coexistencia en un mismo inmueble de unidades de propiedad individual y sectores comunes de propiedad colectiva. La propuesta era vista como una forma de aumentar el número de propietarios de viviendas, una forma de democratización para el acceso a la vivienda en propiedad dirigida a la clase media, los obreros y los asalariados (BALLENT, 2005).

La implementación de esta ley en Mendoza permitió, por ejemplo la venta de unidades individuales del conjunto de Casas Colectivas. Sin embargo no funcionó en la provincia como estímulo a la construcción privada, que comenzó a desarrollarse avanzados los años '60.

\footnotetext{
22 Los planes quinquenales fueron procedimientos de planificación estatal de realizaciones e inversiones. El Primer Plan Quinquenal abarcó el período entre 194 y 1952, el Segundo Plan Quinquenal se desarrolló entre 1952 y 1955.
} 
El único ejemplo que hemos encontrado de intento de aplicación de esta ley para el acceso a la vivienda es el anuncio dentro del Segundo Plan Quinquenal de la construcción de 108 departamentos en monoblock en la ciudad de Mendoza que no llegaron a concretarse por la interrupción del periodo de gobierno a instancias del golpe militar (EVANS, 1955).

\section{Conclusiones}

El problema de la vivienda popular que se inicia fuertemente en las últimas décadas del siglo XIX, se manifestó en toda su magnitud en la primera mitad del siglo $\mathrm{XX}, \mathrm{y}$ sigue siendo hoy en Mendoza, un tema pendiente de resolución.

Entre 1880 y 1920 aproximadamente la injerencia estatal en el tema de la vivienda no pasaba en Mendoza, de disposiciones reguladoras de las prácticas privadas y públicas, particularmente las que afectaban la higiene y seguridad de la población.

En 1910, y a partir del progreso económico aportado por la vitivinicultura a escala provincial,el Estado intentó estimular la inversión privada para la construcción de viviendas de alquiler, casas de vecindad, pasajes, etc. Sin embargo, esta alternativa tuvo escaso desarrollo en Mendoza.

El problema de la vivienda popular continuó sin salidas efectivas durante toda la década del '20. Si bien el Banco Hipotecario Nacional, asistió de modo efectivo en esos años a una parte de la población que podía optar por la autoconstrucción, en forma individual. La gran mayoría de la población no tenía acceso a créditos hipotecarios, ni podía asumir los altos costos de la construcción, por lo cual quedaban sujetos a la inestable situación de inquilinos.

A partir de 1930 y sobre la base de un proyecto económico, orientado hacia la industrialización sustitutiva de importaciones, se producían una serie de modificaciones estructurales que cambiarán las condiciones, tanto en lo que se refiere a la posibilidadde autoabastecimiento de materiales de construcción (cemento y acero), como a las de ejecución de políticas de vivienda en el marco del naciente Estado benefactor. En esta época se desarrolla en Mendoza una nueva tipología de vivienda: la vivienda colectiva en bloque que además de perseguir la finalidad de paliar el problema de la vivienda popular, buscaba "educar" a los sectores de menores recursos (y en esa línea menor educación y cultura) sobre cómo se debía vivir. 
La llegada del peronismo al gobierno, supuso un mayor acceso a la vivienda individual.

En Mendoza desde 1947, el gobierno provincial junto al Instituto Provincial de la Vivienda y Banco Hipotecario Nacional promovieron la ejecución de barrios en los que se consolidaron tipologías arquitectónicas habitacionales que de alguna manera venían conformándose desde principios de siglo XX, como la casa cajón -de planta compactacomo modelo del habitar individual Estas nuevas tipologías habitacionales permitieron el desarrollo de una familia nuclear en un espacio adecuado, higiénico, confortable, económico y más accesible.

En todo este proceso de más de cincuenta años, el acceso de los sectores populares a la vivienda fue desigual y cambiante, marcado por distintas condicionantes generalmente de orden económico o político. Es la autoconstrucción como camino a la posesión de la vivienda propia, la acción de más larga duración que sigue aún hoy, marcando la historia del acceso a los espacios domésticos en Mendoza.

\section{Referencias}

AAVV (1957). Anales de Legislación Argentina (1889-1919), Buenos Aires: Ed. La ley.

ABOY, Rosa (2005). Viviendas para el pueblo. Espacio urbano y sociabilidad en el barrio Los Perales, Buenos Aires: FCE.

ARMUS, Diego (2000)El descubrimiento de la enfermedad como problema social: Lobato, Mirta (dir.). El progreso, la modernización y sus límites (1880-1916), Colección Nueva Historia Argentina, tomo V, Buenos Aires:Sudamericana

BALLENT, Anahí (2004) Vivienda de interés social: Aliata, Fernando y Liernur, Francisco (dir.) Diccionario Histórico de Arquitectura, Hábitat y Urbanismo en la Argentina, Buenos Aires:Clarín, tomo s-z, pp. 176-187.

BALLENT, Anahí (2005). Las huellas de la política. Vivienda, ciudad, peronismo en Buenos Aires, 1943 - 1955,Buenos Aires: UNQ.

BORMIDA, ELIANA ET. AL (1990). Los italianos en la construcción de Mendoza después del terremoto de 1861: Revista de la Universidad de Mendoza, Mendoza: UM. CANO, Guillermo(1935).Labor Gubernativa, tomo $n \circ 2$, septiembre- octubre. 
CANO,Guillermo (1937).Labor Gubernativa, Imprenta Oficial, tomo $n \circ 13$, julioagosto.

CIRVINI, Silvia (1989b). El ambiente urbano en Mendoza a fines del siglo XIX. La higiene social como herramienta del proyecto utópico del orden: Rodríguez y Cerutti (comp.)Arturo Andrés Roig. Filósofo e historiador de las ideas, México: Univ. de Guadalajara.

CIRVINI, Silvia (2004). Nosotros los arquitectos. Campo disciplinar y profesión en la Argentina Moderna, Mendoza: FNA-Zeta.

CIVIT, Manuel y CIVIT, Arturo (1937). Casas colectivas para obreros y empleados de Mendoza: Revista Nuestra Arquitectura no 8.

CONI, Emilio R. (1897). Saneamiento de la Provincia de Mendoza (República Argentina). Buenos Aires: Imprenta de Pablo E. Coni e Hijos.

DE GREGORIO, Roberto. (2006). La casa criolla. Popularmente llamada la casa chorizo. Buenos Aires: Nobuko.

DIARIO LOS ANDES, 10 de febrero de 1946

DÍAZ GUZMÁN, José (1938). Índice general de leyes de la provincia (1896- 1946), $2^{\circ}$ serie, tomo VII (1926- 1937).

EVANS, Carlos (1954).Mensaje 1953-1954, Mendoza: ed. Oficial.

EVANS, Carlos (1955).Mensaje 1954-1955, Mendoza: ed. Oficial.

LECUONA, Diego (1993). Orígenes del problema de la vivienda / 1. Buenos Aires: Centro Editor de América Latina.

LIERNUR, Francisco (1987). Buenos Aires: la estrategia de la casa autoconstruida: Cuaderno de Historia 03,IAA- UBA.

MANZINI, Lorena, (2011). Las viviendas del siglo XIX en Santiago de Chile y la región de Cuyo en Argentina: Revista Universum. № 26 Vol. 2, pp. 165 a 186. MUNICIPALIDAD DE LA CIUDAD DE MENDOZA. (1914). Digesto Municipal (18691913). Mendoza: Imprenta la tarde.

OFICINA DE PRENSA E INFORMACIONES DEL PODER EJECUTIVO (1951). Agua, vivienda y Salud, Mendoza:Ed oficial.

PAIVA, Verónica y SILVESTRI, Graciela. Higienismo: Aliata, Fernando y Liernur, Francisco (dir.) Diccionario Histórico de Arquitectura, Hábitat y Urbanismo en la Argentina, (edición preliminar), Buenos Aires: Clarín, tomo e-h, pp. 153-160. PONTE. Ricardo (2008). Mendoza, aquella ciudad de barro, Mendoza. CONICET 
RAFFA, Cecilia (2006). Un pueblo para 3000 habitantes: las primeras Casas Colectivas para obreros y empleados estatales en Mendoza, 1935-1938: Revista de Historia de América no 134, Costa Rica: IPGH-OEA, pp. 115-139.

RAFFA, Cecilia (2007). El imaginario sanitario en Mendoza a fines del siglo XIX: obras de higiene y salubridad durante la intendencia de Luis Lagomaggiore (1884 - 1888): Revista de Historia Social y de las Mentalidades, Chile: Departamento de Historia de Universidad de Santiago, vol. 2, pp. 173-200.

RAFFA, Cecilia (2009). La vanguardia racionalista en Mendoza: la obra de los arquitectos Manuel y Arturo Civit:Revista de Historia de América no 139, Costa Rica: IPGH- OEA, pp. 181-205.

RIGOTTI,Ana María (1985).Notas en torno a la historia de la vivienda pública en Argentina:Cuadernos del CURDIUR no 14, Rosario.

ROMERO, Luis Alberto (1990). Los sectores populares urbanos como sujetos históricos: Proposiciones n 19, Ediciones sur: Santiago de Chile, pp.28-278. 